\title{
MARCA CIUDAD: NATURALEZA Y ALCANCE DESDE EL HÉXAGONO DE ANHOLT
}

\section{CITY BRAND: NATURE AND SCOPE FROM THE HEXAGON OF ANHOLT}

\author{
Dr.C. Juan Carlos Castro Analuiza
}

http://orcid.org/0000-0002-5371-9727

Doctor en Ciencias de la Empresa (España).

Docente de la Facultad de Ciencias Administrativas, carrera de Mercadotecnia de la Universidad Técnica de Ambato, Ecuador.

juanccastro@uta.edu.ec

Ing. Diana Maribel Sánchez Villalba Ingeniera en Marketing y Gestión de Negocios (Ecuador). Docente de la Facultad de Ciencias Administrativas, carrera de Ciencias Administrativas de la Universidad Técnica de Ambato, Ecuador. dsanchez1270@uta.edu.ec

\section{ARTÍCULO DE INVESTIGACIÓN}

Recibido: 13 de marzo de 2020.

Aceptado: 15 de junio de 2020.

\section{RESUMEN}

El turismo es uno de los sectores con mayor repunte a nivel mundial, y se ha convertido en un elemento clave para el desarrollo socio-económico de las ciudades, a pesar de la diversificación de la oferta turística, esta promueve oportunidades en los destinos pocos conocidos. Por ello, este estudio buscó determinar cuáles son los factores del "Hexágono de Anholt" más significativos, a tomar en cuenta para configurar la percepción que tienen los visitantes al momento de esquematizar la marca-Pelileo. Para ello, se eligió 340 visitantes mayores a 18 años, a quienes se les aplicó una encuesta cara a cara de 32 preguntas. Para finalmente, mostrar que la ciudad de Pelileo es atractiva por la actividad comercial que generan los negocios, además sus residentes crean una atmósfera agradable y sobretodo un ambiente seguro y pacífico, factores significativos que motivan a los visitantes a visitar la ciudad.

Palabras clave: Identidad competitiva, marca ciudad, Hexágono de Anholt

ISSN: 1390-9320, Vol. 7, No. 3, junio 2020 


\section{ABSTRACT}

Tourism is considered to be one of the vital increasing sectors worldwide, resulting as an essential element to the socio-economic development of cities, notwithstanding the diversification of the touristic offer, it promotes opportunities in obscure destinations. Due to this, the investigation endeavored to determine the most compelling factors belonging to the "Anholt Hexagon", to be taken in discussion to configure the perception that visitors have when they devise the Pelileo brand. Hence, 340 visitors over the age of 18 years were chosen, to whom a face to face survey of 32 questions was conducted. To demonstrate that in result, Pelielo city is appealing as a result of the commercial activity engendered by businesses, furthermore its residents who forge an amiable atmosphere and overall a secure and peaceful environment, noteworthy factors that encourage people to visit the city.

Keywords: Competitive identity, city brand, Anholt Hexagon.

\section{INTRODUCCIÓN}

El turismo es una industria activa que forma parte de los sectores económicos a nivel mundial con mayor repunte (Orgaz \&Moral, 2016; Rodríguez \& Granados, 2017). Este sector, genera ingresos por divisas, crea oportunidades de negocio y estimula la instauración de tecnología (Brida, Monterubbianesi \& Zapata, 2011; Vargas \& Chaviano, 2017). Según la Organización Mundial de Turismo (OMT) a inicios del 2019 existió un incremento del $4 \%$ en el turismo internacional, destaca Oriente Medio (+8\%), Asia y Pacífico (+6\%), Europa y África (4\%) y las Américas (3\%).

Estas cifras son alentadoras para el Ecuador, según datos del Ministerio de Turismo (MINTUR, 2018) los destinos más visitados son las ciudades de Quito $(60,77 \%)$, Guayaquil (38,34\%) y Cuenca (14,43\%). Entre enero y noviembre del 2019 el ingreso de visitantes extranjeros al Ecuador ascendió a 1.381.726 procedentes de España, con un crecimiento del 15,8\%; EE. UU (15,1\%); Francia (12,2\%); Canadá (10,6\%) y Alemania (4,5\%).

Por tanto, resulta muy importante y propicio el estudio del turismo vinculado a la creación de una marca ciudad como elemento de fortaleza e identidad competitiva (Holguín \& Becerra, 2016; Pritchard \& Morgan, 2011) que promueva procesos de desarrollo cultural, social y económico en los territorios (García, 2010; Paredes \& Moreno, 2016). 
Las ciudades con frecuencia, enfrentan situaciones en su entorno en las que es imposible prestar atención a todas sus necesidades. Por ello, hemos considerado abordar esta propuesta mediante tres factores: cognitivo (características físicas), afectivo (valores motivacionales), global (congrega el factor cognitivo y afectivo) (Álvarez, 2015; De Alcântara Buosi, De Oliveira \& Da Silva, 2017; Gunn, 1972; Stern \& Krakover, 1993).

Estos tres factores aportan a la creación de una marca ciudad visto desde el Hexágono de Anholt, que agrupa: presencia, lugar, potencial, pulso, personas y prerrequisitos (Cañas, \& Gómez, 2014; Castro, Herrera, Martínez, Quisimalin \& Pérez del Campo, 2018), elementos que evalúan los aspectos más sobresalientes de una ciudad en su contexto (Corbacho, Valderrama \& García, 2014; Rodríguez \& Quijano, 2017).

Investigaciones anteriores han sugerido que la ciudad se sitúa en la mente de las personas por su contenido y significado. Es decir, la implicación de los procesos internos de los visitantes construye esquemas informativos anticipatorios que permite contrastar las diferentes ciudades en base a la oferta Andrade (2016). Por tanto, la esencia de una marca y su significado perduran en función de su valor, cultura y personalidad (De los Reyes, Ruiz, \& Zamarreño, 2017).

Estos tres elementos definen la identidad competitiva de una ciudad bajo sus propias referencias y características (Andrade, 2016; Sáez, Mediano \& Elizagarate, 2011) para atraer inversión, optimizar el comercio y el turismo (Holguín \& Becerra, 2016). Estos elementos y la interacción del entorno hacen posible la evolución de la actividad turística en las ciudades.

Nueva York en la década de los 70s establece la frase "I love New York" (Irigoyen, 2017), impulsada por la campaña "The Big Apple", esto generó la salida de la ciudad en crisis, hasta convertirse en una ciudad cosmopolita de diversión y dinamismo (Heredero \& Chaves, 2015; De los Reyes et al., 2017). Por otro lado, Londres en 2012 lanza la marca “Totally London" por la conmemoración de los Juegos Olímpico de ese año (Saéz, Mediano \& de Elizagarate, 2011; Yejas, 2016) determinándose a la ciudad como destino ideal para el desarrollo de oportunidades (Heredero \& Chaves, 2015). Finalmente, en el estudio de Larios, Estrada \& Luna (2015) definen a Celaya como ciudad dinámica de desarrollo en el turismo industrial y en la gestión cultural, bajo la denominación "Puerta de Oro del Bajío". 
Con este contexto, él estudió se interiorizó mediante el modelo "Hexágono de Anholt" propicio para la evaluación de la marca ciudad (Anholt, 2006; Castro et al., 2018). Este modelo hace parte del índice Anholt GMI City Brand y está configurado por seis factores: 1) presencia, 2) lugar; 3) potencial, 4) pulso, 5) gente y 6) prerrequisitos. Estos seis factores permiten establecer la reputación de las diferentes ciudades fuera de sus límites (Mariutti, Giraldi, \& Costa, 2013) expresando su significado en la identidad competitiva (Larios et al., 2015).

La marca-ciudad ha demostrado una evidente eficacia en países desarrollados, afianzando las relaciones entre los gestores del turismo (ciudadanos, gobierno, actores sociales entre otros.). No obstante, la evidencia empírica es mínima en los países en vías de desarrolla. Por tanto, el alcance se configuró en la siguiente pregunta de investigación ¿Cuáles son los factores del "Hexágono de Anholt" a tomar en cuenta para configurar la percepción que tienen los visitantes al momento de esquematizar la marcaPelileo? (Fierro, Zuñiga, Castillo \& Mazo, 2015).

Interrogante que permitió definir el objetivo del estudio basado en los factores del hexágono de Anholt (presencia, lugar, potencial, pulso, gente y prerrequisitos) como se exponen a continuación: Determinar cuáles son los factores del "Hexágono de Anholt" más significativos, a tomar en cuenta para configurar la percepción que tienen los visitantes al momento de esquematizar la marca-Pelileo.

Definido el alcance prospectivo del estudio y matizado en los factores del Hexágono de Anholt (presencia, lugar, potencial, pulso, gente y prerrequisitos) se dio paso a las definiciones hipotéticas de la marca-ciudad. Con esto se buscó asociar la importancia, la arquitectura, los lugares, la seguridad, los negocios que presenta la ciudad de Pelileo (Fierro et al., 2015; Galván \& Larios, 2015; Herrera, Martínez \& Castro, 2018; Segovia \& Gómez, 2017) como se muestra en la figura 1. 
Planteamiento de las Hipótesis

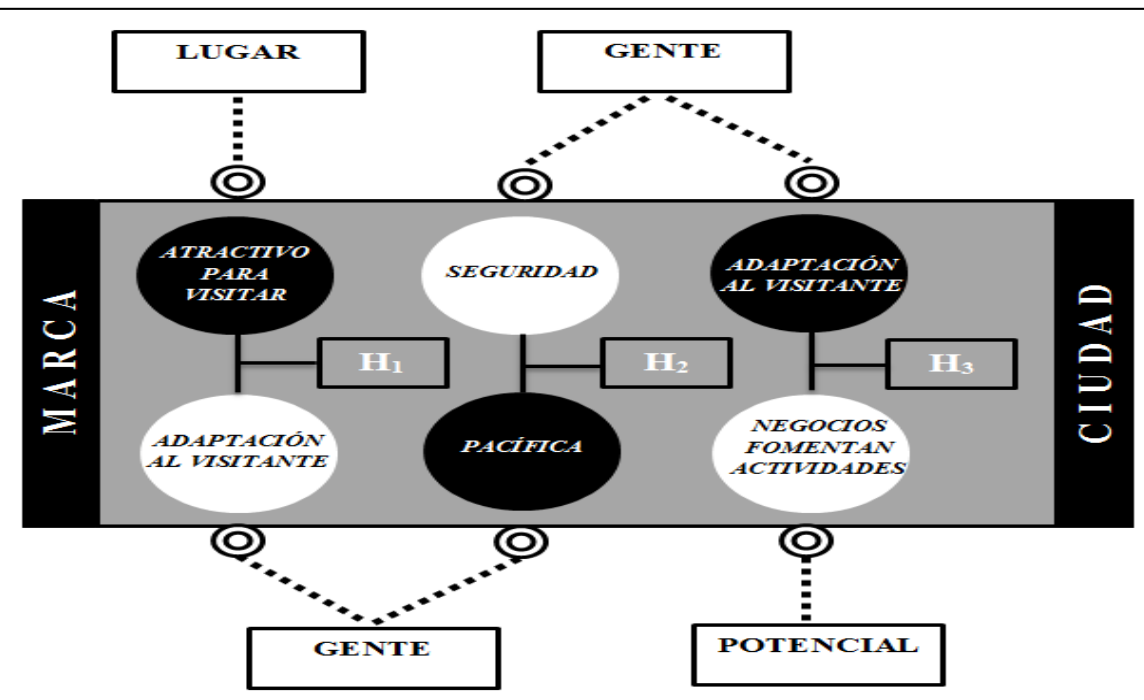

Nota: Se presenta las 3 hipótesis del estudio de la Marca-Pelileo, en base al modelo del Hexágono de Anholt. En la $\mathrm{H}_{1}$, se relacionan los factores gente y lugar, donde destaca "adaptación al visitante" y "atractiva para visitar" respectivamente. $\mathrm{La} \mathrm{H}_{2}$ se basa en el factor gente, en este sobresale "seguridad" y "pacífica". Finalmente, la $\mathrm{H}_{3}$ muestra la dependencia entre gente y potencial, en donde resalta la "adaptación al visitante" y "negocios fomentan actividades", respectivamente.

Figura 1. Formulación de hipótesis de la Marca-Pelileo.

Fuente: Elaboración propia.

Con el registro hipotético como guía del estudio la importancia de la marca-ciudad en un destino turístico representa una referencia diferenciadora que marca la identidad de la ciudad de acuerdo a elementos naturales, esencias culturales o hechos sociales que se cristalizan en acciones de importancia y valoración (Navarro, 2015) promovidas por acciones del city marketing (Ruiz \& Gandâra, 2017) como eje de una estrategia de internacionalidad y de reconocimiento del destino (Garrocho, 2017; Prada \& Pesántez, 2017; Sánchez \& Moura, 2005). Bajo esto preceptos, se plantea las hipótesis: $\mathrm{H}_{1}$ : La adaptación del visitante está asociada con el atractivo de la ciudad.

La seguridad es un factor del sistema turístico, que debe estar orientado a la protección de los usuarios como una necesidad básica (Amorin, Gandara, Tarlow \& Korstanje, 2012; de Liz, de Fátima Teston, Verdinelli, Hipólito \& Amorim, 2018). Este elemento, se ha convertido en una característica para la selección del destino (Fernandes, Lacay \& Gândara, 2016). Por tanto, son los habitantes de la ciudad que deben difundir información positiva del lugar, originar una cultura de seguridad y de manejo integral de

ISSN: 1390-9320, Vol. 7, No. 3, junio 2020 
las zonas (Bringas \& Verduzco, 2008; Orgaz \& Moral, 2016), con la iniciativa de generar espacios seguros para los turistas. Bajo este postulado, se presenta la $\mathrm{H}_{2}$ : La seguridad de la ciudad está asociada con una convivencia pacífica del destino.

El comercio es el principal impulso económico de las ciudades más activas del mundo (Garrocho, 2017), como parte de los procesos comerciales se encuentra la extracción, producción, transformación, prestaciones e intercambios (Navarro, 2015) que generan progreso para el sector que lo realiza. Por tanto, dentro del abastecimiento turístico, el comercio es una tipología que se convierte en la primera motivación del turista (Perona \& Molina, 2016; Varisco, 2005) para visitar el destino con el objetivo de adquirir productos. En base a estos criterios, se enmarca la $\mathrm{H}_{3}$ : La variedad de negocios está asociada con actividades comerciales interesantes.

\section{MATERIAL Y MÉTODOS}

La naturaleza metodológica del estudio se enmarcó en un enfoque cuantitativo de naturaleza transversal y nivel relacional. Esta orientación metodológica, incluyó la descripción de los participantes, el diseño del estudio, la delineación del instrumento y su procedimiento (Cadena-Iñiguez et al., 2017; Hernández, Fernández \& Baptista, 2014). Esto permitió establecer las diversas estructuras que permitió determinar los factores del "Hexágono de Anholt" más significativos, a tomar en cuenta para configurar la percepción que tienen los visitantes de la marca-Pelileo (Müggenburg-Rodríguez \& Pérez-Cabrera, 2007; Pulido, 2015).

\subsection{Participantes}

Los participantes que fueron incluidos en el estudio fueron personas (sexo femeninomasculino, mayores a 18 años) que visitaron la ciudad los fines de semana (sábadosdomingo), de las tres regiones del Ecuador (Sierra, Costa, Oriente) en familia y grupo de amigos, principalmente para realizar compras (jeans, muebles, pantuflas, artesanías y sombreros) en los diferentes negocios que presenta la ciudad (Guevara, 2016).

La muestra $(n=340)$ que se utilizó por economía de tiempo y recursos fueron visitantes que frecuentaban los principales negocios de la ciudad. Se aplicó un muestreo probabilístico estratificado, que permitió dividir a los diferentes subgrupos o estratos (jeans, muebles, pantuflas, artesanías y sombreros) se consideró un nivel de confianza 
del $95 \%(Z=1,96 ; p=q=50)$ y un error de muestreo del $5 \%$ 2017) (Cadena-Iñiguez et al., 2017; Hernández et al., 2014; Otzen \& Manterola, 2017).

\subsection{Método}

En la investigación se utilizó un diseño factorial de reducción de factores permitiéndonos encontrar grupos homogéneas de variables (presencia, lugar, potencial, pulso, gente y prerrequisitos) dispuestos en el modelo del Hexágono de Anholt (López, \& Fachelli, 2016). A partir del conjunto de variables se realizó la matriz de correlaciones donde se mostró los factores que se encuentran asociados, además se presentó la prueba KMO y Bartlett, para dar paso a la extracción de factores, mediante el método de componentes principales que estimó las puntuaciones factoriales a partir de las variables con mayor significancia y la matriz de cargas factoriales.

Con esto, se identificó el número de factores, mediante el criterio de sedimentación, representación gráfica donde se mostró los factores y autovalores, para finalmente presentar la rotación de los factores, mediante el método varimax, que minimizó el número de factores con cargas altas y mejorar su interpretación (Ledesma, Ferrando, \& Tosi, 2019; Méndez \& Rondón, 2012).

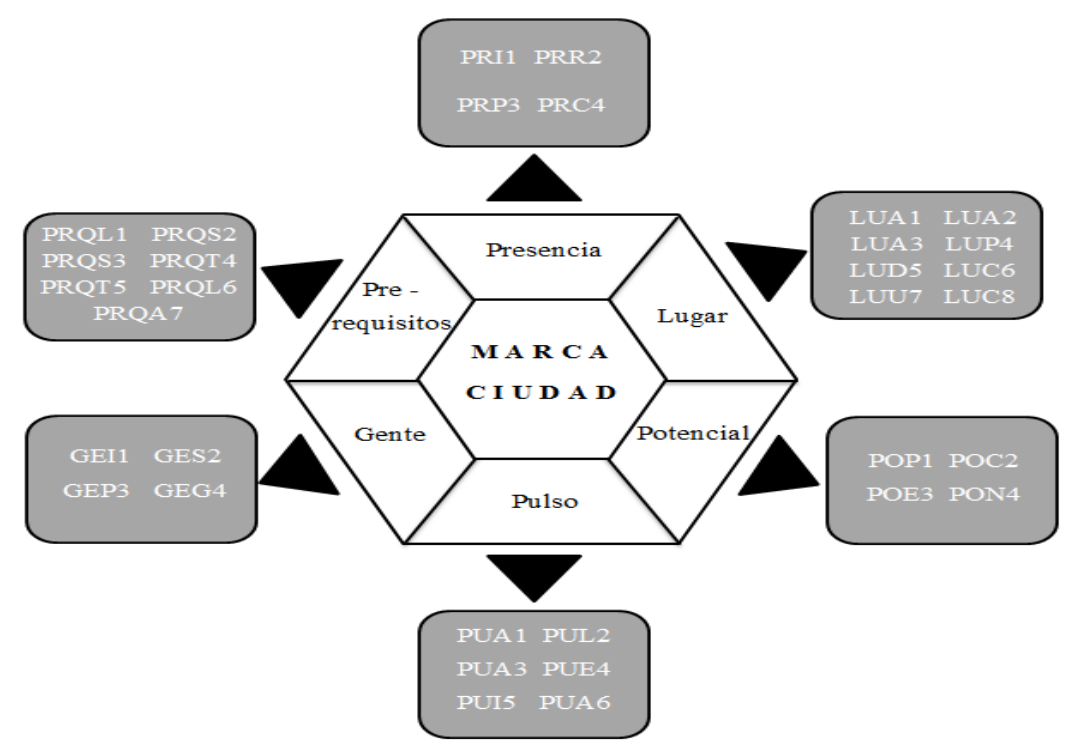

Nota: Operacionalización de los factores según los seis componentes del Hexágono de Anholt, en donde se codifica (1) PRESENCIA PRI1: Importancia, PRR2: Reconocimiento, PRP3: Percepción, PRC4: Contribución; (2) LUGAR LUA1: Atractivos para visitar, LUA2: Atractivos para vivir, LUA3: Arquitectura, LUP4: Paisajes, LUD5: Diseño urbano, LUC6: Clima, LUU7: Ubicación, LUC8: Contaminación; (3) POTENCIAL POP1: Proyectos, POC2: Centro educativos, POE3: Empleo, PON4: Negocios; (4) PULSO PUA1: Actividades al aire libre, PUC2: Centro educativos, PUA3: Actividades Comerciales, PUE4: Entretenimiento, PUI5: Infraestructura, PUA6: Actividades culturales; (5) GENTE GEI1: Inmigrantes, GES2: Seguridad, GEP3: Pacífica, GEG4: Gente amigable; (6) PRE-REQUISITOS PRQL1: Limpio, PRQS2: Servicios básicos, PRQS3: Salud y educación, PRQT4: Transporte, PRQT5: Telecomunicaciones, PRQL6: Locales comerciales, PRQA7: Acceso. Adaptado de "La Marca Ciudad Celeya como Estrategia de Inserción al City Marketing: Diagnóstico Preliminar: Ejes de crítica y reflexión en torno a la cultura y al desarrollo" por E. Larios, S. Estrada y J. Luna, 2015, pp. 129. Copyright por Pearson. 
En la operacionalización dispuesta en el estudio, se consideró el Hexágono de Anholt que identifica la identidad competitiva de una ciudad, mediante seis constructos: presencia, lugar, potencial, pulso, gente y prerrequisitos (Larios et al., 2015).

La presencia fue medida mediante cuatro ítems (PRI1, PRR2, PRP3, PRC4), estos permitieron identificar el reconocimiento de la ciudad. El lugar, denotó ocho ítems (LUA1, LUA2, LUA3, LUP4, LUD5, LUC6, LUU7, LUC8), que valoraron lo atractivo y bello que muestra el destino. El potencial se midió en base a cuatro ítems (POP1, POC2, POE3, PON4), que consideraron la calidad de educación y economía de la ciudad.

El pulso se valoró con seis ítems (PUA1, PUL2, PUA3, PUE4, PUI5, PUA6), que determinaron el estilo de vida de los residentes. La gente se midió mediante cuatro ítems (GEI1, GES2, GEP3, GEG4), estos apreciaron el valor intangible que tiene la ciudad. Finalmente, los prerrequisitos fueron evaluados con siete ítems (PRQL1, PRQS2, PRQS3, PRQT4, PRQT5, PRQL6, PRQA7), que estimaron los aspectos diferenciados del lugar.

\subsubsection{Tipo de instrumento}

Se utilizó una encuesta cara a cara, técnica que permitió el diseño de un cuestionario semi-estructurado definido según los componentes del Hexágono de Anholt: presencia, lugar, potencial, pulso, gente y prerrequisitos (López \& Fachelli, 2015). Estos componentes permitieron identificar la imagen destino de la ciudad de Pelileo, de cara a la percepción que tienen los visitantes acerca de este destino (Lafuente \& Marín, 2008; Ramírez \& Zwerg, 2012; Rendón, Villasís \& Miranda, 2015, 2016).

\subsubsection{Diseño del instrumento}

Constó de 33 ítems con escala de Likert ( 1 totalmente en desacuerdo y 5 totalmente de acuerdo) así se evaluó la imagen destino de Pelileo matizado mediante los seis componentes del Hexágono de Anholt (presencia, lugar, potencial, pulso, gente y prerrequisitos) 


\subsection{Validación del instrumento (prueba piloto).}

Tabla 1. Variabilidad y media de los ítems y de la suma total (prueba piloto)

\begin{tabular}{|c|c|c|c|c|}
\hline Factores & Código & Ítems & Media & Varianza \\
\hline \multirow[t]{4}{*}{ Presencia } & PRI1 & Importancia & 3,71 & 1,975 \\
\hline & PRR2 & Reconocida & & \\
\hline & PRP3 & Percepción & 3,63 & 1,417 \\
\hline & PRC4 & Contribución & 3,43 & 1,958 \\
\hline \multirow[t]{8}{*}{ Lugar } & LUA1 & Atractiva para visitar & 2,09 & 1,434 \\
\hline & LUA2 & Atractiva para vivir & 2,34 & 1,938 \\
\hline & LUA3 & Arquitectura & 2,40 & 2,129 \\
\hline & LUP4 & Paisajes & 3,09 & 1,491 \\
\hline & LUD5 & Diseño urbano & 2,94 & 1,703 \\
\hline & LUC6 & Clima & 2,77 & 1,417 \\
\hline & LUU7 & Ubicación & 3,57 & 1,605 \\
\hline & LUC8 & Contaminación & 3,26 & 1,726 \\
\hline \multirow[t]{4}{*}{ Potencial } & POP1 & Proyectos de vida & 3,26 & 1,550 \\
\hline & POC2 & Centros educativos & 3,06 & 1,879 \\
\hline & POE3 & Empleo & 3,11 & 1,634 \\
\hline & PON4 & Negocios & 3,57 & 2,017 \\
\hline \multirow[t]{6}{*}{ Pulso } & PUA1 & Actividades al aire libre & 2,49 & 2,022 \\
\hline & PUL2 & Lugares & 3,26 & 1,726 \\
\hline & PUA3 & Actividades comerciales & 4,06 & 1,703 \\
\hline & PUE4 & Entretenimiento & 3,11 & 2,281 \\
\hline & PUI5 & Infraestructura & 2,71 & 2,387 \\
\hline & PUA6 & Actividades culturales & 3,57 & 2,076 \\
\hline \multirow[t]{4}{*}{ Gente } & GEl1 & Inmigrantes & 3,09 & 1,257 \\
\hline & GES2 & Seguridad & 2,91 & 2,434 \\
\hline & GEP3 & Pacífica & 3,26 & 1,491 \\
\hline & GEG4 & Gente amigable & 3,14 & 1,832 \\
\hline \multirow[t]{7}{*}{ Prerrequisitos } & PRQL1 & Limpia & 3,09 & 1,492 \\
\hline & PRQS2 & Servicios básicos & 3,37 & 1,299 \\
\hline & PRQS3 & Salud y educación & 3,69 & 1,457 \\
\hline & PRQT4 & Transporte & 3,43 & 1,723 \\
\hline & PRQT5 & Telecomunicaciones & 3,2 & 1,518 \\
\hline & PRQL6 & Locales comerciales & 2,86 & 1,479 \\
\hline & PRQA7 & Acceso & 3,94 & 1,644 \\
\hline
\end{tabular}

Nota: Factores: Factores de investigación (presencia, lugar, potencial, pulso, gente y prerrequisitos). Ítem y código. Varianza: Valores por ítem. Media: Valores por ítem.

Fuente: Elaboración propia.

En la prueba piloto, el factor presencia (cuatro ítems) tiene un promedio de la varianza de $p=S^{2}=1,783$, en este factor el ítem con mayor variabilidad $\left(S^{2}=1,975\right)$ fue la "importancia de la ciudad dentro de Tungurahua". Con respecto a el factor lugar (ocho 
ítems), el promedio de variabilidad fue de $p=S^{2}=1,680$, el valor más representativo $\left(S^{2}=2,129\right)$ fue en el ítem "la arquitectura es atractiva".

En relación al factor potencial (cuatro ítems) el promedio de la varianza fue de $\mathrm{p}=\mathrm{S}^{2}=1,770$, el ítem con mayor puntación en este factor $\left(\mathrm{S}^{2}=2,017\right)$ fue "se puede hacer negocios". Referente al factor pulso (seis ítems) el promedio de la varianza fue de $p=S^{2}=2,033$, el ítem más relevante $\left(S^{2}=2,387\right)$ fue "posee infraestructura para actividades".

En cuanto al factor gente (cuatro ítems) la variabilidad promedio fue de $p=S^{2}=1,753$, el valor más alto de la varianza en este factor $\left(S^{2}=2,434\right)$ fue "segura y sin delincuencia". Finalmente, el factor prerrequisitos (siete ítems) el promedio de varianza fue de $\mathrm{p}=\mathrm{S}^{2}=1,516$, se destacó $\left(\mathrm{S}^{2}=1,723\right)$ el ítem "el servicio de transporte público es bueno".

\subsubsection{Análisis Factorial Exploratorio (prueba piloto)}

p1 $=$ Determinante $=5,646 \mathrm{E}-16$

$<0,05$

Tabla 2. Prueba KMO y Bartlett (prueba piloto)

\begin{tabular}{llr}
\hline \multicolumn{2}{l}{ Medida Kaiser-Meyer-Olkin de adecuación de muestreo } &, $\mathbf{0 8 1}$ \\
& Aprox. Chi-cuadrado & 778,280 \\
Prueba de esfericidad de Bartlett & Gl & 528 \\
& p-valor &, 000
\end{tabular}

Nota: Medida Kaiser-Meyer-Olkin: Contrasta si las correlaciones parciales entre los factores son adecuadamente pequeñas. Prueba de esfericidad de Bartlett: Indica la pertinencia del modelo factorial. Fuente: Elaboración propia.

El resultado del determinante fue de 5,646E-16, esto indicó que los factores están linealmente relacionados. Por otro lado, en la prueba de esfericidad de Bartlett el p-valor está por debajo de 0,05 y la medida de Kaiser-Meyer-Olkin fue de 0,081, por lo que no es aceptable y se busca la estabilidad de los ítems. 
Tabla 3. Matriz de varianza total explicada (prueba piloto)

\begin{tabular}{|c|c|c|c|c|c|c|c|c|c|}
\hline \multirow[t]{2}{*}{ Comp. } & \multicolumn{3}{|c|}{ Autovalores iniciales } & \multicolumn{3}{|c|}{$\begin{array}{l}\text { Sumas de extracción } \\
\text { de cargas al cuadrado }\end{array}$} & \multicolumn{3}{|c|}{$\begin{array}{c}\text { Sumas de rotación } \\
\text { de cargas al } \\
\text { cuadrado }\end{array}$} \\
\hline & Total & $\% \mathrm{~S}^{2}$ & $\begin{array}{c}\% \\
\text { Acum. }\end{array}$ & Total & $\% \mathrm{~S}^{2}$ & $\begin{array}{c}\% \\
\text { Acum. }\end{array}$ & Total & $\% S^{2}$ & $\begin{array}{c}\% \\
\text { Acum. }\end{array}$ \\
\hline 1 & 4,04 & 12,24 & 12,24 & 4,04 & 12,24 & 12,24 & 3,85 & 11,66 & 11,66 \\
\hline 2 & 3,35 & 10,15 & 22,38 & 3,35 & 10,15 & 22,38 & 2,94 & 8,91 & 20,57 \\
\hline 3 & 2,76 & 8,35 & 30,73 & 2,76 & 8,35 & 30,73 & 2,85 & 8,63 & 29,20 \\
\hline 4 & 2,58 & 7,81 & 38,55 & 2,58 & 7,81 & 38,55 & 2,61 & 7,92 & 37,12 \\
\hline 5 & 2,30 & 6,96 & 45,51 & 2,30 & 6,96 & 45,51 & 2,38 & 7,23 & 44,34 \\
\hline 6 & 1,97 & 5,97 & 51,47 & 1,97 & 5,97 & 51,47 & 2,35 & 7,13 & 51,47 \\
\hline 7 & 1,77 & 5,36 & 56,83 & & & & & & \\
\hline 8 & 1,62 & 4,91 & 61,74 & & & & & & \\
\hline 9 & 1,52 & 4,60 & 66,34 & & & & & & \\
\hline 10 & 1,40 & 4,23 & 70,57 & & & & & & \\
\hline 11 & 1,26 & 3,80 & 74,38 & & & & & & \\
\hline 12 & 1,14 & 3,45 & 77,83 & & & & & & \\
\hline 13 & 1,08 & 3,28 & 81,11 & & & & & & \\
\hline 14 & 0,99 & 2,99 & 84,09 & & & & & & \\
\hline 15 & 0,76 & 2,30 & 86,39 & & & & & & \\
\hline 16 & 0,74 & 2,23 & 88,62 & & & & & & \\
\hline 17 & 0,59 & 1,78 & 90,40 & & & & & & \\
\hline 18 & 0,56 & 1,69 & 92,10 & & & & & & \\
\hline 19 & 0,53 & 1,60 & 93,70 & & & & & & \\
\hline 20 & 0,48 & 1,44 & 95,14 & & & & & & \\
\hline 21 & 0,40 & 1,20 & 96,34 & & & & & & \\
\hline 22 & 0,27 & 0,81 & 97,14 & & & & & & \\
\hline 23 & 0,25 & 0,75 & 97,89 & & & & & & \\
\hline 24 & 0,20 & 0,61 & 98,50 & & & & & & \\
\hline 25 & 0,14 & 0,41 & 98,91 & & & & & & \\
\hline 26 & 0,12 & 0,36 & 99,27 & & & & & & \\
\hline 27 & 0,10 & 0,30 & 99,57 & & & & & & \\
\hline 28 & 0,07 & 0,22 & 99,79 & & & & & & \\
\hline 29 & 0,04 & 0,11 & 99,90 & & & & & & \\
\hline 30 & 0,02 & 0,05 & 99,95 & & & & & & \\
\hline 31 & 0,01 & 0,04 & 99,99 & & & & & & \\
\hline 32 & 0,00 & 0,01 & 100,00 & & & & & & \\
\hline 33 & 0,00 & 0,00 & 100,00 & & & & & & \\
\hline
\end{tabular}

Nota: Método de extracción: Análisis de componentes principales (6). Auto valores: Formula la cantidad de la varianza total que está expuesta por cada factor. Los porcentajes de varianza explicada están asociados a cada factor se consiguen dividiendo su auto valor por la suma de los auto valores. Además, se extrae tantos factores como auto valores mayores $>1$.

Fuente: Elaboración propia. 
En la prueba piloto existió 13 auto valores mayores que 1, el procedimiento que se llevó acabo extrajo 6 factores que explican el $51,471 \%$ de la varianza de los datos, lo que implica más del $50 \%$ de la varianza total.

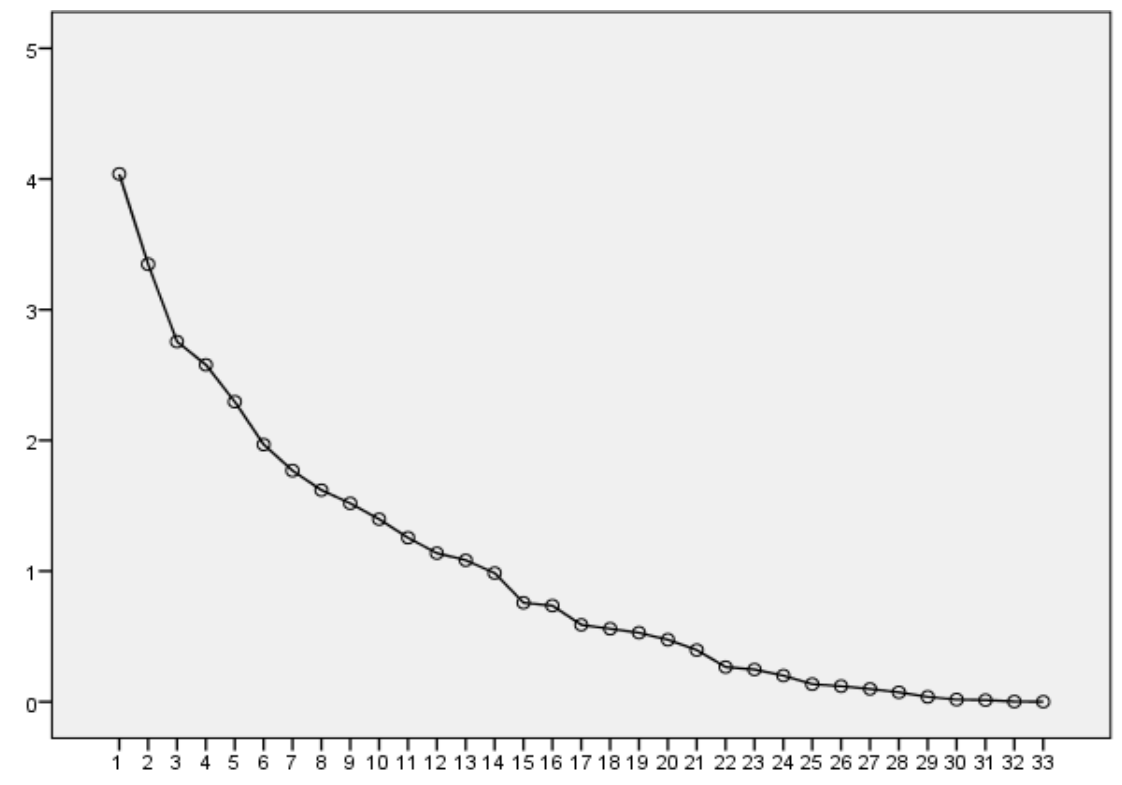

Nota: Gráfico de sedimentación: Muestra una representación gráfica de la magnitud de los autovalores. El corte en la tendencia descendente sirve de regla para la determinación del número óptimo de factores que deben estar presentes en la solución.

"El eje de las " $x$ " se encuentra el número de factores y en el eje de las "y" el número de autovalores.

Figura 3. Sedimentación del instrumento (prueba piloto)

Fuente: Elaboración propia

En la sedimentación con 33 ítems, se identificó que la pendiente pierde inclinación a partir del catorceavo autovalor, por lo que se extrajo por iniciativa los 6 primeros factores, estos suman la mayor parte de la variación $(51,471 \%)$ del total de los datos. 
Tabla 4. Componentes rotados del instrumento (prueba piloto)

\begin{tabular}{|c|c|c|c|c|c|c|}
\hline & & & Comr & iente & & \\
\hline & 1 & 2 & 3 & 4 & 5 & 6 \\
\hline Paisajes & (693 &,- 215 & ,328 &,- 084 & ,004 &,- 107 \\
\hline Limpia & 665 & ,405 & ,342 &,- 090 &,- 128 &, 131 \\
\hline Diseño urbano & 626 & 052 &,- 137 &,- 069 &,- 085 & 032 \\
\hline Proyectos de vida & ,574 &,- 497 & ,017 & ,126 &,- 149 &,- 278 \\
\hline Importancia & ,546 &,- 004 & ,002 &,- 008 & ,034 & ,243 \\
\hline Empleo & ,496 &, 140 &,- 151 & ,347 &,- 142 &,- 196 \\
\hline Servicios Básicos & ,433 & ,059 & , 160 &,- 234 & ,392 &,- 191 \\
\hline Pacifica & ,429 &,- 128 & 201 & ,257 & ,135 &,- 068 \\
\hline Actividades comerciales & 367 &,- 037 &,- 097 & 001 & ,314 &,- 010 \\
\hline Actividades culturales & ,298 &,- 115 &,- 222 &,- 062 & ,082 &, 115 \\
\hline Negocios & , 015 & ,714 & ,066 &,- 085 &,- 168 &,- 144 \\
\hline Atractiva para vivir &,- 035 & 681 & ,092 & ,010 & ,180 & ,316 \\
\hline Seguridad &,- 215 & 614 & ,039 & , 412 & ,153 & ,002 \\
\hline Arquitectura &,- 036 & ,503 & 372 & ,060 &,- 083 &,- 048 \\
\hline Percepción & ,052 &, 493 &,- 360 &,- 109 & ,184 &,- 324 \\
\hline Atractiva para visitar & , 165 & ,214 &, 669 &,- 037 &,- 125 &,- 057 \\
\hline Infraestructura & ,040 & 215 &, 642 & 015 & ,059 & ,116 \\
\hline Contribución & ,093 &, 140 &,- 637 &,- 232 &,- 061 & ,073 \\
\hline Lugares & , 105 & 133 &,- 494 &,- 048 &,- 488 & ,098 \\
\hline Gente amigable &,- 161 &,- 195 & ,053 &, 730 &,- 071 & ,238 \\
\hline Contaminación & ,127 & ,212 &,- 019 &, 687 &,- 111 & ,117 \\
\hline Inmigrantes & ,472 &,- 123 &, 116 &, 490 & ,447 &,- 037 \\
\hline Salud y educación &,- 078 & ,054 & ,281 &, 463 & , 177 &,- 030 \\
\hline Actividades al aire libre &, 305 & ,167 &,- 289 &,- 398 & , 187 &, 107 \\
\hline Reconocida & ,073 & , 166 &, 378 & , 169 &,- 720 & , 120 \\
\hline Entretenimiento &,- 086 & , 191 &, 166 &,- 052 & \begin{tabular}{|l|}
, 584 \\
\end{tabular} & ,061 \\
\hline Ubicación & ,264 & ,260 &,- 185 & ,344 &, 516 &, 161 \\
\hline Locales comerciales & 070 &,- 080 &,- 083 & , 138 &,- 173 & \begin{tabular}{|l|}
.703 \\
\end{tabular} \\
\hline Centros educativos &, 555 &,- 261 &,- 086 &,- 012 &,- 093 &,- 563 \\
\hline Transporte &, 140 &,- 240 & ,040 & ,246 & ,347 & ,493 \\
\hline Acceso & ,332 & ,242 &,- 033 &,- 177 &,- 040 & ,484 \\
\hline Telecomunicaciones &,- 215 & ,016 &,- 402 & 123 &,- 007 &, 473 \\
\hline Clima & ,164 &,- 028 &,- 319 & , 434 &,- 293 &,- 439 \\
\hline
\end{tabular}

Nota: Método de extracción: Análisis de componentes principales (6). Método de rotación Varimax: Minimiza el número de factores que tienen saturaciones altas en cada factor optimizando la solución por columna. Los números en negrilla pertenecen a cada factor según su ítem.

aLa rotación ha convergido en 18 iteraciones, este es el número máximo que los algoritmos realizan para la solución factorial final.

Fuente: Elaboración propia.

Factor 1: Paisajes (LUP4), limpia (PRQL1), diseño urbano (LUD5), proyectos de vida (POP1), importancia (PRI1), empleo (POE3), servicios básicos (PRQS2), pacífica 
(GEP3), actividades comerciales (PUA3), actividades culturales (PUA6), actividades al aire libre (PUA1) y centros educativos (POC2). Factor 2: negocios (PON4), atractiva para vivir (LUA2), seguridad (GES2), arquitectura (LUA3), percepción (PRP3) contribución (PRC4) y lugares (PUL2). Factor 3: atractiva para visitar (LUA1), infraestructura (PUI5) y reconocida (PRR2). Factor 4: gente amigable (GEG4), contaminación (LUC8), inmigrantes (GEl1), salud y educación (PRQS3) y clima (LUC6). Factor 5: entretenimiento (PUE4) y ubicación (LUU7). Factor 6: locales comerciales (PRQL6), transporte (PRQT4), acceso (PRQA7) y telecomunicaciones (PRQT5).

Tabla 5. Consistencia de varianza y Alpha de Combrach por factor (prueba piloto)

\begin{tabular}{lrrr}
\hline Factores & N. Ítems & Varianza & Alpha a \\
\hline Presencia & 4 & 5,350 & 0,332 \\
Lugar & 8 & 13,443 & 0,609 \\
Potencial & 4 & 7,080 & 0,902 \\
Pulso & 6 & 12,195 & 0,079 \\
Gente & 4 & 7,014 & 0,551 \\
Prerrequisitos & 7 & 10,612 & 0,559 \\
\hline Varianza Global & & $\mathbf{5 5 , 6 9 4}$ & \\
\hline Alpha a Global & & $\mathbf{0 , 8 3 2}$ \\
\hline
\end{tabular}

Nota: Factores: variable de la investigación. N. Ítems: número de ítems por factor. Varianza: valores por factor. Alpha $\alpha$ : Valores por factor.

Fuente: Elaboración propia.

En el cálculo de Alpha de Combrach los factores presencia, lugar, pulso, gente y prerrequisitos, mostraron resultados no aceptables $(<0,8)$, mientras que el potencial y el cálculo global $(0,832)$ de todos los factores son aceptables.

\subsection{Subsanación de ítems}

Realizada la prueba piloto se perpetró las siguientes correcciones en la sección identidad competitiva para la aplicación definitiva del cuestionario.

Para medir correctamente el constructo potencial se modificó los cuatro ítems que conforman este factor. Se tomó como prioridad evaluar la economía como indicador más sobresaliente de la ciudad en base al comercio, se cambió las siguientes preguntas:

- "Se puede desarrollar proyectos de vida" por "presenta una variedad de negocios". 
- "Posee buenos centros educativos" por "cuenta con negocios interesantes".

- "Se puede encontrar empleo" por "los negocios fomentan actividades interesantes".

- "Se puede hacer negocios" por "la ciudad ofrece condiciones adecuadas para realizar actividades comerciales".

En el constructo pulso el ítem "existen actividades comerciales", se enfocó a la evaluación del factor potencial por lo que se eliminó, además se cambiaron las siguientes interrogantes:

- "Hay entretenimiento y/o se puede visitar" por "existe sitios de entretenimiento y ocio".

- "Posee infraestructura para actividades" por "fomenta actividades interesantes"

En el factor gente se restructuró la siguiente pregunta para evaluar de manera apropiada a los visitantes de la ciudad:

- "Los inmigrantes se adaptan con facilidad" por "facilita la adaptación del visitante"

En el constructo prerrequisitos se modificó cuatro de los siete ítems para un mejor entendimiento de las preguntas, estos fueron:

- "La luz, agua, alcantarillado funcionan bien" por "cuenta con servicios básicos para los visitantes".

- "Los servicios de salud y educación básica, son buenos" por "ofrecen atención primaria de salud"

- "El servicio de telecomunicaciones es bueno" por "es adecuado los servicios de telefonía, radio, tv e internet"

- "Tiene buena oferta de locales comerciales" por "los negocios y restaurantes brindan condiciones adecuadas para los visitantes".

\subsection{Procedimiento}

Se aplicó el cuestionario al total de la muestra (340) de acuerdo al siguiente detalle: jeans (167), muebles (83), pantuflas (55), artesanías (28) y sombreros (7) (Medina, 2017), en los días 2, 9 y 16 de noviembre del 2019, con un total de 68 entrevistadores, 
quienes fueron estudiantes de la Universidad Técnica de Ambato que fueron capacitados el 31 de octubre del 2019. Los entrevistadores se dividieron en dos grupos de 22 y uno de 24 personas para cada fecha respectivamente, se aplicó las encuestas en los diferentes puntos de la hoja de ruta establecida, cada entrevistador realizó 5 encuestas a los visitantes de la ciudad.

\section{RESULTADOS}

\subsection{Matriz de correlaciones mediante la prueba de KMO y Bartlett}

Análisis Factorial Exploratorio (prueba piloto)

Determinante $=7,953 \mathrm{E}-8$

$<0,05$

Tabla 6. Prueba KMO y Bartlett.

Medida Kaiser-Meyer-Olkin de adecuación de muestreo

Prueba de esfericidad de Bartlett

p-valor , 000

Nota: Medida Kaiser-Meyer-Olkin: Contrasta si las correlaciones parciales entre los factores son adecuadamente pequeñas. Prueba de esfericidad de Bartlett: Indica la pertinencia del modelo factorial.

Fuente: Elaboración propia.

El resultado del determinante fue de 7,953E-8, esto indicó que los factores están linealmente relacionados. Por otro lado, en la prueba de esfericidad de Bartlett el p-valor está por debajo de 0,05 y la medida de Kaiser-Meyer-Olkin fue de 0,922 lo que indica que es meritorio utilizar el análisis factorial.

\subsection{Extracción de Factores mediante el método de componentes principales}

Tabla 7. Matriz de varianza total explicada.

\begin{tabular}{|c|c|c|c|c|c|c|c|c|c|}
\hline \multirow[t]{2}{*}{ Comp. } & \multicolumn{3}{|c|}{ Autovalores iniciales } & \multicolumn{3}{|c|}{$\begin{array}{l}\text { Sumas de extracción } \\
\text { de cargas al cuadrado }\end{array}$} & \multicolumn{3}{|c|}{$\begin{array}{c}\text { Sumas de rotación de } \\
\text { cargas al cuadrado }\end{array}$} \\
\hline & Total & $\% S^{2}$ & $\begin{array}{c}\% \\
\text { Acum }\end{array}$ & Total & $\% S^{2}$ & $\begin{array}{c}\% \\
\text { Acum }\end{array}$ & $\begin{array}{c}\text { Tota } \\
\text { I }\end{array}$ & $\% S^{2}$ & $\begin{array}{c}\% \\
\text { Acum. }\end{array}$ \\
\hline 1 & 11,61 & 36,28 & 36,28 & 11,61 & 36,28 & 36,28 & 5,00 & 15,64 & 15,64 \\
\hline 2 & 1,76 & 5,50 & 41,78 & 1,76 & 5,50 & 41,78 & 4,43 & 13,83 & 29,47 \\
\hline
\end{tabular}




\begin{tabular}{|c|c|c|c|c|c|c|c|c|c|}
\hline 3 & 1,71 & 5,35 & 47,13 & 1,71 & 5,35 & 47,13 & 3,22 & 10,08 & 39,55 \\
\hline 4 & 1,59 & 4,97 & 52,10 & 1,59 & 4,97 & 52,10 & 3,20 & 10,01 & 49,56 \\
\hline 5 & 1,14 & 3,56 & 55,66 & 1,14 & 3,56 & 55,66 & 1,71 & 5,35 & 54,91 \\
\hline 6 & 1,07 & 3,33 & 58,99 & 1,07 & 3,33 & 58,99 & 1,30 & 4,07 & 58,99 \\
\hline 7 & 0,96 & 3,00 & 61,99 & & & & & & \\
\hline 8 & 0,93 & 2,89 & 64,88 & & & & & & \\
\hline 9 & 0,90 & 2,81 & 67,69 & & & & & & \\
\hline 10 & 0,83 & 2,60 & 70,29 & & & & & & \\
\hline 11 & 0,81 & 2,54 & 72,83 & & & & & & \\
\hline 12 & 0,73 & 2,28 & 75,11 & & & & & & \\
\hline 13 & 0,64 & 1,99 & 77,09 & & & & & & \\
\hline 14 & 0,60 & 1,86 & 78,96 & & & & & & \\
\hline 15 & 0,58 & 1,82 & 80,78 & & & & & & \\
\hline 16 & 0,55 & 1,70 & 82,48 & & & & & & \\
\hline 17 & 0,51 & 1,61 & 84,09 & & & & & & \\
\hline 18 & 0,50 & 1,55 & 85,64 & & & & & & \\
\hline 19 & 0,48 & 1,49 & 87,13 & & & & & & \\
\hline 20 & 0,47 & 1,46 & 88,58 & & & & & & \\
\hline 21 & 0,43 & 1,34 & 89,92 & & & & & & \\
\hline 22 & 0,40 & 1,24 & 91,16 & & & & & & \\
\hline 23 & 0,38 & 1,18 & 92,34 & & & & & & \\
\hline 24 & 0,35 & 1,09 & 93,43 & & & & & & \\
\hline 25 & 0,35 & 1,08 & 94,51 & & & & & & \\
\hline 26 & 0,32 & 0,99 & 95,50 & & & & & & \\
\hline 27 & 0,28 & 0,86 & 96,36 & & & & & & \\
\hline 28 & 0,27 & 0,85 & 97,21 & & & & & & \\
\hline 29 & 0,27 & 0,85 & 98,06 & & & & & & \\
\hline 30 & 0,23 & 0,71 & 98,77 & & & & & & \\
\hline 31 & 0,20 & 0,63 & 99,39 & & & & & & \\
\hline 32 & 0,19 & 0,61 & $\begin{array}{l}100,0 \\
0\end{array}$ & & & & & & \\
\hline
\end{tabular}

Nota: Método de extracción: Análisis de componentes principales (6). Auto valores: Formula la cantidad de la varianza total que está expuesta por cada factor. Los porcentajes de varianza explicada están asociados a cada factor se consiguen dividiendo su auto valor por la suma de los auto valores. Además, se extrae tantos factores como auto valores mayores $>1$.

Fuente: Elaboración propia.

En esta matriz existió 6 auto-valores mayores que 1, el procedimiento que se estableció extrajo 6 primeros factores que explican el 58,99\% de la varianza de los datos, lo que implica más del $50 \%$ de la varianza total. 


\subsection{Determinación del número de factores mediante el gráfico de sedimentación}

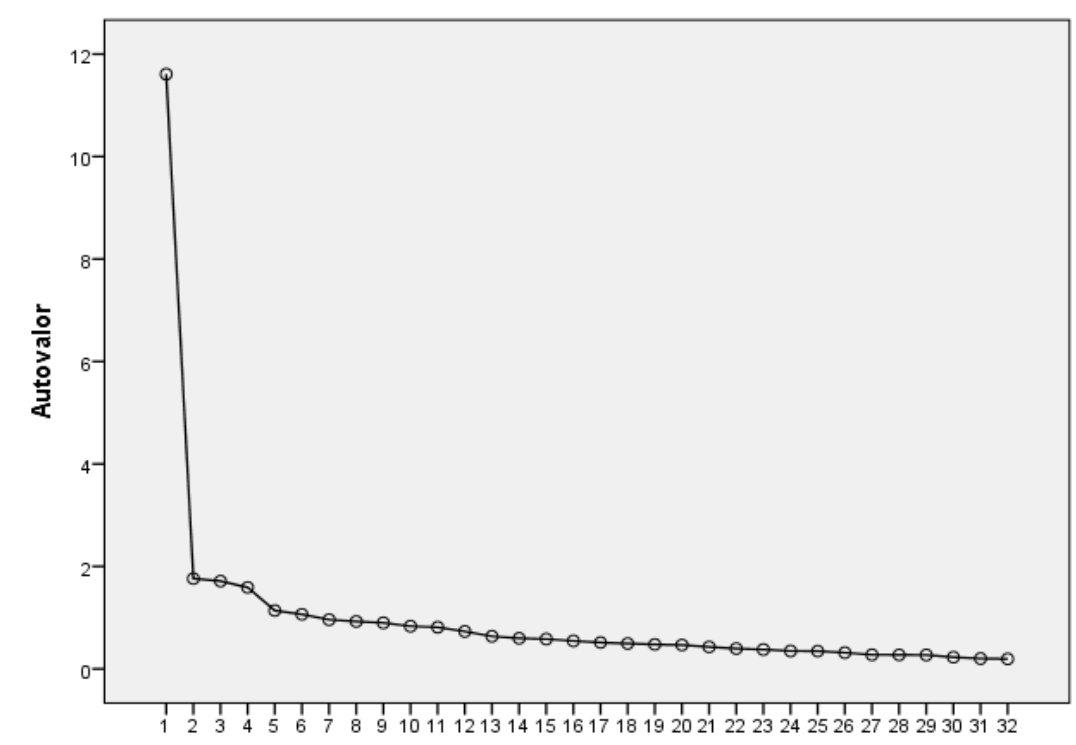

Nota: Gráfico de sedimentación: Muestra una representación gráfica de la magnitud de los auto-valores. El corte en la tendencia descendente sirve de regla para la determinación del número óptimo de factores que deben estar presentes en la solución.

"El eje de las " $x$ " se encuentra el número de factores y en el eje de las "y" el número de auto-valores.

Figura 4. Sedimentación del instrumento

Fuente: Elaboración propia.

En la sedimentación con 32 ítems, se identificó que la pendiente pierde inclinación a partir del sexto autovalor, por lo que se extrajo los 6 primeros factores, estos suman la mayor parte de la variación $(51,471 \%)$ del total de los datos. 


\subsection{Rotación de los factores mediante el método Varimax}

Tabla 8. Componentes rotados del instrumento.

\begin{tabular}{|c|c|c|c|c|c|c|}
\hline & \multicolumn{6}{|c|}{ Componente } \\
\hline & 1 & 2 & 3 & 4 & 5 & 6 \\
\hline Entretenimiento & ,722 & , 165 & ,025 & ,148 & ,221 &,- 142 \\
\hline Arquitectura & ,699 & , 166 & 295 & ,078 & , 104 &,- 003 \\
\hline Atractiva para vivir & ,668 & , 169 & 173 & ,230 & ,060 &,- 136 \\
\hline Lugares & 648 & ,202 & 216 & ,117 & , 108 & ,157 \\
\hline Actividades interesantes & ,608 & , 184 & ,143 & ,125 & ,469 &,- 019 \\
\hline Paisajes & ,582 & ,251 & 292 & ,210 & ,142 & ,283 \\
\hline Diseño urbano & ,562 & , 159 & 390 & ,095 & ,111 & ,047 \\
\hline Negocios fomentan actividades & ,520 & ,519 & ,103 & ,289 &,- 191 &,- 039 \\
\hline Actividades al aire libre &, 516 & ,298 & 211 & ,091 & , 149 & ,136 \\
\hline Variedad de negocios & ,358 & ,717 & ,004 & ,006 & ,050 &,- 162 \\
\hline Percepción & ,055 & 665 & 202 & 121 & 201 & ,024 \\
\hline Importancia & 228 & ,646 &,- 096 & 238 & 195 & 176 \\
\hline Gente amigable & 279 & ,581 & ,438 & 166 & 141 &,- 119 \\
\hline Atractiva para visitar & ,365 & 577 & ,440 &,- 038 & 087 &,- 042 \\
\hline Adaptación al visitante & 312 & 575 & 343 & ,266 & 197 &,- 080 \\
\hline Reconocida & ,022 & 519 & ,036 & 375 & ,076 & ,218 \\
\hline Condiciones para comercializar & ,395 & ,500 & 081 & ,370 &,- 101 & ,002 \\
\hline Ubicación & 284 & ,493 & 201 & 332 &,- 048 & 235 \\
\hline Negocios interesantes & ,074 & ,388 &, 111 &,- 118 & ,169 & ,258 \\
\hline Seguridad & 262 & 108 & 714 & ,165 &,- 069 & ,019 \\
\hline Pacífica & ,082 & ,293 & 695 & ,255 &,- 019 &,- 033 \\
\hline Contaminación & ,248 &,- 102 & ,578 & 169 &,- 062 & ,255 \\
\hline Limpia & 221 & 345 & ,519 & 260 & 276 & ,046 \\
\hline Clima & 272 & 105 &, 509 & 032 & 351 & ,060 \\
\hline Transporte & ,159 & ,085 & ,190 & ,757 & ,201 &,- 014 \\
\hline Acceso &,- 049 & 143 & 245 & 685 & 294 & 141 \\
\hline Salud primaria & ,441 & ,270 & 040 & ,619 &,- 005 &,- 100 \\
\hline Telecomunicaciones & 381 - & ,062 & 263 & -598 &,- 025 &,- 136 \\
\hline Servicios básicos & 319 & 332 r r & ,162 &, 463 & 245 - - & , 105 \\
\hline Actividades culturales & ,254 & ,173 &,- 124 & 192 &, 653 &,- 071 \\
\hline $\begin{array}{l}\text { Condiciones adecuadas para } \\
\text { visitantes }\end{array}$ & 201 & 215 & 255 & ,392 &, 554 & ,014 \\
\hline Contribución &,- 038 & ,072 & ,069 & ,009 &,- 059 & ,867 \\
\hline
\end{tabular}

Nota: Método de extracción: Análisis de componentes principales (6). Método de rotación Varimax: Minimiza el número de factores que tienen saturaciones altas en cada factor optimizando la solución por columna. Los números en negrilla pertenecen a cada factor según su ítem.

aLa rotación ha convergido en 9 iteraciones, este es el número máximo que los algoritmos realizan para la solución factorial final.

Fuente: Elaboración propia. 
El primer factor está conformado por: entretenimiento (PUE3), arquitectura (LUA3), atractiva para vivir (LUA2), lugares (PUL2), actividades interesantes (PUA4), paisajes (LUP4), diseño urbano (LUD5), negocios fomentan actividades (PON3) y actividades al aire libre (PUA1). En base al modelo utilizado estos pertenecen a los factores pulso, lugar y potencial, de esta manera se conformó el factor ocio y diversión.

El segundo factor contempla los siguientes ítems: variedad de negocios (POV1), percepción (PRP3), importancia (PRI1), gente amigable (GEG4), atractiva para visitar (LUA1), adaptación al visitante (GEA1), reconocida (PRR2), condiciones para comercializar (POC4), ubicación (LUU7) y negocios interesantes (PON2). Estos ítems son parte de los factores de potencial, presencia gente, lugar y potencial, se consideró a este nuevo factor como desarrollo comercial.

El tercer factor está compuesto por: seguridad (GES2), pacífica (GEP3), contaminación (LUC8), limpia (PRQL1) y clima (LUC6). Estos ítems pertenecen a los factores de gente, lugar y prerrequisitos, a partir de la conformación de los nuevos ítems se establece el factor ambientación. El cuarto factor consta de los siguientes ítems, transporte (PRQT4), acceso (PRQA7), salud primaria (PRQS3), telecomunicaciones (PRQT5), y servicios básicos (PRQS2). Estos ítems pertenecen al factor prerrequisitos, por lo que toma el nombre de condiciones de la ciudad.

En el quinto factor se extrajo los siguientes ítems: actividades culturales (PU5) y condiciones adecuadas para visitantes (PRQC6). Estos ítems corresponden a los factores pulso y prerrequisitos, que conforman el factor cultura. Finalmente, en el sexto factor se estableció el ítem contribución (PRC4), es parte del factor prerrequisitos, que conforman un destino de contribución. 


\subsection{Gráfico de correlaciones significativas.}

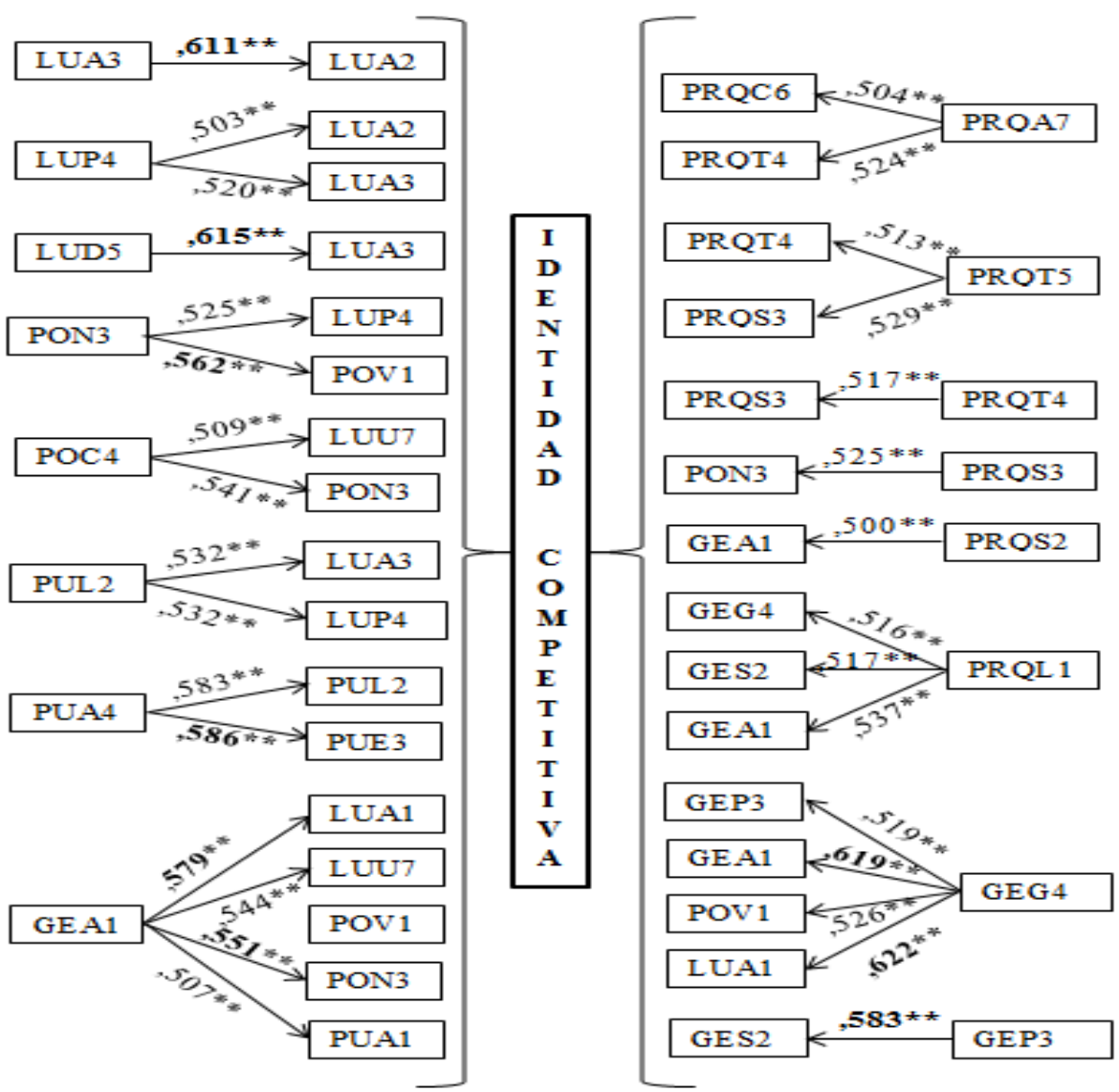

Nota: Matriz de correlación ítems. Código: especifica al ítem al que pertenece. Números: valores de las correlaciones. $\left(^{*}\right)$ Significativa a nivel 0,05. $\left(^{* *}\right)$ Significativa a nivel 0,01 . Se extrajo las significancias con valores $\geq 0,5$.

Fuente: Elaboración propia.

En el análisis de las correlaciones entre los ítems existieron significancias solamente positivas. Los valores plasmados en la gráfica 5 son $\geq 0,5$ considerados aceptables, sin embargo, el $90 \%$ de los ítems se correlacionaron.

Entre los ítems positivos y con mayor significancia a nivel 0,05 fueron: LUA1 "atractiva para visitar" y GEG4 "gente amigable" $\left(r=0,622^{* *}\right)$, GEA1 "adaptación al visitante" y GEG4 "gente amigable" ( $\left.r=0,619^{\star *}\right)$, LUD5 "diseño urbano" y LUA3 "arquitectura" $\left(r=0,615^{\star *}\right)$ y, LUA3 "arquitectura" y LUA2 "atractiva para vivir" $\left(r=0,611^{* *}\right)$, estos fueron resultados $>0,6$. Además, están las correlaciones significativas $>0,5$, se mencionan los resultados más relevantes: PUA4 "actividades interesantes" y PUE3 "entretenimiento" 
$\left(r=0,586^{* *}\right)$, PUA4 "actividades interesantes" y PUL2 "lugares" $\left(r=0,583^{* \star}\right)$, GES2 "seguridad" y GEP3 "pacífica" $\left(r=0,583^{* *}\right)$, GEA1 "adaptación al visitante" y LUA1 "atractiva para visitar" $\left(r=0,579^{* *}\right)$, PON3 "negocios fomentan actividades" y POV1 "variedad de negocios" $\left(r=0,562^{* *}\right)$, finalmente GEA1 "adaptación al visitante" y PON3 "negocios fomentan actividades" ( $\left.r=0,551^{* *}\right)$.

\subsection{Comprobación de las hipótesis}

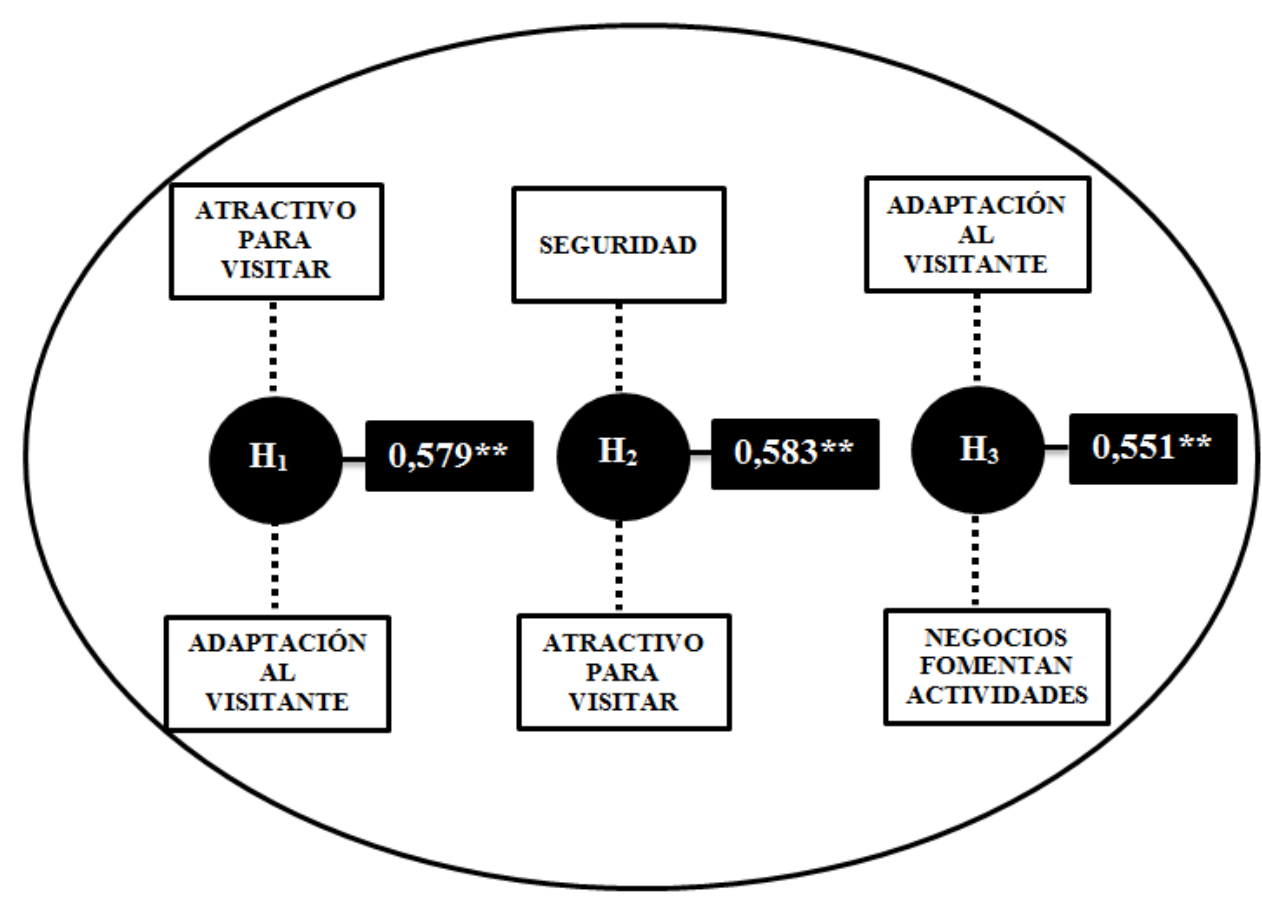

Nota: Se presenta las 3 hipótesis del estudio de la Marca-Pelileo, en base al modelo del Hexágono de Anholt, con la significancia a nivel 0,01 en los resultados.

Figura 6. Comprobación de las hipótesis de la Marca-Pelileo Fuente: Elaboración propia.

H1: La adaptación del visitante está asociada con el atractivo de la ciudad.

La relación entre "adaptación al visitante" y "atractiva para visitar" tienen un nivel de significancia de $\left(r=0,579^{\star *}\right)$. Esto significa que la identidad competitiva de la marca Pelileo tiene una significancia moderada y se acepta la hipótesis.

H2: La seguridad de la ciudad está asociada con una convivencia pacífica del destino. 
La dependencia entre "seguridad" y "pacífica" poseen un nivel de significancia de ( $r=$ $\left.0,583^{* *}\right)$, el resultado es moderado y se acepta la hipótesis.

H3: La variedad de negocios está asociada con actividades comerciales interesantes.

La asociación entre "adaptación al visitante" y "negocios fomentan actividades" conservan un nivel de significancia de $\left(r=0,551^{* *}\right)$, este es moderada y se acepta la hipótesis.

\section{DISCUSIÓN}

Los visitantes de una ciudad son quienes construyen la imagen externa del destino con experiencias positivas o negativas percibidas del lugar. En el estudio se planteó determinar cuáles son los factores del "Hexágono de Anholt" más significativos, a tomar en cuenta para configurar la percepción que tienen los visitantes al momento de esquematizar la marca-Pelileo. Se seleccionó una muestra de 340 visitantes (hombres y mujeres mayores de 18 años) quiénes evaluaron una encuesta de 33 ítems.

Bajo este planteamiento, la relación entre "adaptación al visitante" y "atractiva para visitar" $(r=0,579)$ refleja la adaptación efectiva del visitante a la ciudad. Esto significa que la ciudad es atractiva por los negocios y sus principales actividades comerciales (Regalado et al., 2012; Hernández-Mogollon et al., 2018). Esto factor evidencia cuan atractiva es la ciudad principalmente los fines de semana y feriados festivos, especialmente los turistas visitan el Tambo (jeans), Huambalo (muebles), Benítez (pantuflas), Salasaca (artesanías) y Pamatug (sombreros) territorios donde se concentra el eje económico de la ciudad.

La dependencia entre la "adaptación al visitante" y los "negocios fomentan actividades" $\left(r=0,551^{* *}\right)$ revela que los residentes de la ciudad fomentan hospitalidad y desarrollan actividades que atraen a los visitantes (Regalado et al., 2009; Galván \& Larios, 2015). Las actividades (ferias, desfiles, promociones temporales) se relacionan con los diversos productos (jeans, muebles, pantuflas, artesanías y sombreros) que son fabricados por los habitantes del destino, convirtiéndose en la principal motivación de los turistas para que visiten la ciudad.

La relación de "seguridad" y "pacífica" $\left(r=0,583^{* *}\right)$ reflejan la confianza del visitante con respecto a la ciudad percibida como segura y pacífica para el desarrollo de las diferentes 
actividades que se pueden realizar (Regalado et al., 2012). Bajo esta percepción, se muestra a la ciudad como destino tranquilo y de convivencia en paz, fuera de peligro para los visitantes que realizan diferentes actividades; a esto se suma la amabilidad y carisma de los residentes como embajadores de la marca ciudad Pelileo.

\section{CONCLUSIONES}

La ciudad se ha convertido en un referente de la industria manufacturera del Ecuador, Pelileo se muestra al público con una variedad de productos elaborados por las manos hábiles de los residentes, los mismos que crean una atmósfera agradable en los diferentes sectores que se encuentran. Esto ha generado una atracción de interés en los visitantes y genera una demanda positiva de turistas cada fin de semana y feriados festivos.

Pelileo se muestra como una ciudad interesante que genera emociones positivas al momento de ser visitada e impulsa una herencia económica para sus habitantes y forja una demanda competitiva que moviliza activamente ejes de desarrollo que denota en las actividades que se involucran los jeans, muebles, pantuflas, artesanías y sombreros.

Finalmente, el destino crea confianza en los visitantes, al exponer la minimización de riesgos en el territorio y la excelente hospitalidad turística de los actores principales (residentes, empresa privada y pública), por este motivo se considera a Pelileo como destino de retorno sin riego y de carácter comercial (turismo comercial).

\section{REFERENCIAS BIBLIOGRÁFICAS}

Álvarez, A. (2015). Imagen, Lealtad y Promoción Turística. Análisis con Ecuaciones Estructurales. Revista de Turismo y Patrimonio Cultural, 13(3), 629-648. Recuperado de https://www.redalyc.org/articulo.oa?id=88136217012

Amorin, E., Gandara, J. M., Tarlow, P., \& Korstanje, M. (2012). Seguridad percibida en la ciudad de Curutiba. Un sondeo exploratorio en residentes locales y turistas. Revista de análisis turístico, (14), 1-9. https://doi.org/10.1234/RAT2011n11

Andrade, D. (2016). Estrategias de marketing digital en la promoción de Marca Ciudad. Revista Escuela de Administración de Negocios, 80, 59-72. Recuperado de http://www.redalyc.org/articulo.oa?id=20645903005 
Anholt, S. (2006). The Anholt-GMI City Brands Index: How the world sees the world's cities. Place Branding, 2(1), 18-31. doi:10.1057/palgrave.pb.5990042

Brida, J. G., Monterubbianesi, P. D., \& Zapata-Aguirre, S. (2011). Impactos del turismo sobre el crecimiento económico y el desarrollo. El caso de los principales destinos turísticos de Colombia. Revista de Turismo y Patrimonio Cultural, 9(2), 291-303. Recuperado de https://www.redalyc.org/articulo.oa?id=881/88117284006

Bringas, N., \& Verduzco, B. (2008). La construcción de la frontera norte como destino turístico en un contexto de alertas de seguridad. Región y sociedad, 20(42), 336. Recuperado de https://www.redalyc.org/articulo.oa?id=10204201

Cadena-Iñiguez, P., Rendón-Mendel, R., Aguilar-Ávila, J., Salinas-Cruz, E., CruzMorales, F., \& Sangerman-Jarquín, D. (2017). Métodos cuantitativos, métodos cualitativos o su combinación de la Investigación: un acercamiento en las ciencias sociales. Revista Mexicana de Ciencias Agrícolas, 8 (7), 1603-1617. https://doi.org/10.29312/remexca.v8i7.515

Cañas, L., \& Gómez, L. (2014). Marca país. Experiencias en América y la realidad en Colombia. Bogotá, Colombia: CESA.

Castro, J., Herrera, C., Martínez, L., Quisimalin, M., \& Pérez del Campo, E. (2018). Marca ciudad revisión sistemática y meta-análisis: desde el hexágono de Anholt. European Academic of Management and Business Economics, 1074-1102. Recuperado de https://www.researchgate.net/publication/327581462

Corbacho, J. M., Valderrama, M., \& García, S. (2014). La imagen de la Marca España en las redes a través de su campaña "I need Spain". Historia y Comunicación Social, 19, 501-512. https://doi.org/10.5209/rev_HICS.2014.v19.44980

De Alcântara Buosi, M. C., De Oliveira, S. H., \& Da Silva, Á. (2017). Relación entre la percepción del desarrollo sustentable y la imagen del lugar según los residentes de un destino de turismo internacional. Estudios y Perspectiva en Turismo, 26(1), 128-149. Recuperado de https://www.redalyc.org/articulo.oa?id=180749182007 
De Liz, E. M., De Fátima, S., Verdinelli, M. A., Hipólito, M. M., \& Amorim, E. (2018). La seguridad como promoción del bienestar de un destino turístico: el caso de Balneario Camboriú (Santa Catarina, Brasil). Estudios y perspectivas en turismo, 27(4), 1018-1030. Recuperado de https://www.estudiosenturismo.com.ar/PDF/V27/N04/v27n4a14.pdf

De los Reyes, E., Ruiz, E., \& Zamarreño, G. (2017). Marca territorio y marca ciudad, utilidad en el ámbito del turismo. El caso de Málaga. Internacional Journal of Scientific Management and Tourism, 3(2), 155-174. Recuperado de https://www.researchgate.net/publication/316438547

Fernández, D. L., Lacay, M. A. C., \& Gândara, J. M. G. (2016). La influencia de la seguridad pública en la satisfacción y en la formación de la imagen de Curitiba (Brasil) para el visitante y los visitados. Estudios y perspectivas en turismo, 25(4), 416-438. Recuperado de https://www.estudiosenturismo.com.ar/PDF/V25/N04/v25n4a02\%20.pdf

Fierro, Á., Zuñiga, A., Castillo, M., \& Mazo, C. (2015). Análisis del city branding y la imagen de marca a través de los medios de comunicación online y el social media: caso Medellín (Colombia). Revista Espacios, 36(18), 17. Recuperado de https://www.revistaespacios.com/a15v36n18/15361818.html

Galván, C., \& Larios, E. (2015). Marketing de turismo sustentable para el área natural protegida el Culiacán y la Gavia, Guanajuato: Diagnostico de la identidad y orgullo para una marca ciudad. Revista de Divulgación Científica Jóvenes en la Ciencia, 1(3), 65-70. Recuperado de http://www.jovenesenlaciencia.ugto.mx/index.php/jovenesenlaciencia/article/vie w/774

García, J. S. (210). Marketing para ciudades: las ciudades también se venden, las ciudades también son producto. Pensar la Publicidad. Revista Internacional de Investigaciones Publicitaria, 4(1), 211-226. Recuperado de https://revistas.ucm.es/index.php/PEPU/article/view/PEPU1010120211A/15183

Garrocho, C. (2017). EST y la importancia de las ciudades. Economía, sociedad y territorio, 17(53). http://dx.doi.org/10.22136/est0020171019 
Guevara, R. (2016). El estado del arte en la investigación: ¿análisis de los conocimientos acumulados o indagación por nuevos sentidos? Folios, (44), 165-179. Recuperado de http://www.scielo.org.co/pdf/folios/n44/n44a11.pdf

Gunn, C. (1972), Vacationscape: Desingning tourist region. Austin: Bureau of Business Research, University of Texas.

Heredero, O., \& Chaves, M. (2015). Las asociaciones "Marca Producto" y "Marca Ciudad" como estrategia de "city marketing". Una aproximación a los casos de Nueva York, París y Londres. Área Abierta, 15(2), 63-76. https://doi.org/10.5209/rev_ARAB.2015.v15.n2.47857

Hernández, R., Fernández, C., \& Baptista, M. (2014). Metodología de la Investigación. México DF: McGRAW-Hill.

Herrera, C. L., Martínez, L. A., \& Castro, J. C. (2018). Marca ciudad: revisión sistematica desde el hexágono de Anholt. Revista mktDescubre, 1(11) 3-14. Recuperado de http://revistas.espoch.edu.ec/index.php/mktdescubre/article/view/148

Holguín, A. M., \& Becerra, V. C. (2016). Imagen e identidad, unidad clave en el logro de la marca ciudad. Revista Legado de Arquitectura y Diseño, (20), 27-34. Recuperado de https://www.redalyc.org/jatsRepo/4779/477950133015/html/index.html

Irigoyen, C. O. (2017). La cita con el destino para el futuro de la marca ciudad Juárez. Nóeisis. Revista de Ciencias Sociales y Humanidades, 26(52), 152-158. http://dx.doi.org/10.20983/noesis.2017.2.7

Lafuente, C., \& Marín, A. (2008). Metodología de la investigación en las ciencias sociales: Fases, fuentes y selección de técnicas. Revista Escuela de $\begin{array}{llll}\text { Administración de } \quad \text { 5egocios, } & \text { (64), }\end{array}$ https://doi.org/10.21158/01208160.n64.2008.450

Larios, E., Estrada, S., \& Luna, E., (2015). La Marca Ciudad Celaya, como Estrategia de Inserción al City Marketing: Diagnóstico Preliminar. En Contreras, R., RuizRueda, H. y Molina, R. (coord.), Ejes de crítica y reflexión en torno a la cultura y al desarrollo. (pp. 119-137). México: Pearson. 
Ledesma, R. D., Ferrando, P. J., \& Tosi, J. D. (2019). Uso del Análisis Factorial Exploratorio en RIDEP. Recomendaciones para Autores y Revisores. Revista iberoamericana de diagnóstico y evaluación psicológica, 3(52), 173-181.

López P., \& Fachelli, S. (2015). Metodología de la investigación social cuantitativa. Barcelona: CC BY-NC-ND

López-Roldan, P., \& Fachelli, S. (2016). Análisis factorial. Metodología de la investigación social cuantitativa, 5-134.

Mariutti, F. G., Giraldi, J. de M. E., \& Costa, A. L. (2013). "Brazil's image abroad: How Can the Public and Private Sector Partnership Improve Marketing Strategies?". Tourism Planning \& Development, 10(1), 110-119. https://doi.org/10.1080/21568316.2012.723040

Medina, M. (2017). Propuesta de desarrollo del turismo accesible en la reserva de biósfera Isla de Ometepe. Revista de Turismo y Patrimonio Cultural. 15 (4), 913-924. Recuperado de https://www.researchgate.net/publication/321040256

Méndez, C., \& Rondón, M. (2012). Introducción al análisis factorial exploratorio. Revista Colombia de Psiquiatría, 41 (1), 197-207. 10.1016/S0034-7450(14)60077-9

Ministerio del turismo (diciembre, 2019). Movimientos Internos: GEOVIT. Quito. Recuperado de https://servicios.turismo.gob.ec/index.php/turismo-cifras/201809-19-17-01-51/movimientos-internos-geovit

Ministerio del turismo (diciembre, 2019). Promedio de llegada de visitantes extranjeros a Ecuador creció en 2019. Quito. Recuperado de https://www.turismo.gob.ec/promedio-de-llegada-de-visitantes-extranjeros-aecuador-crecio-4-en-2019/

Müggenburg, V. M., \& Pérez, I. (2007). Tipos de estudio en el enfoque de investigación $\begin{array}{lllll}\text { cuantitativa. Enfermería } & \text { Universitaria. } 4 \text { (1), 35-38. }\end{array}$ https://doi.org/10.22201/eneo.23958421e.2007.1.469

Navarro, D. (2015). Recursos turísticos y atractivos turísticos: conceptualización, clasificación y valoración. Cuadernos de turismo, (35), 335-357. https://www.redalyc.org/pdf/398/39838701014.pdf 
Organización Mundial del Turismo (mayo, 2019). Turismo internacional: Aumenta las cifras y la confianza. (PR No. PR 19034). Madrid. Recuperado de https://www.unwto.org/es/global/press-release/2019-05-21/turismointernacional-aumentan-las-cifras-y-la-confianza

Orgaz, F., \& Moral, S. (2016). El turismo como motor potencial para el desarrollo económico de zonas fronterizas en vías de desarrollo. Un estudio de caso. EI periplo sustentable, (31). Recuperado de http://www.scielo.org.mx/scielo.php?script=sci_arttext\&pid=S1870$90362016000200008 \& \operatorname{lng}=e s \&$ tIng $=e s$

Otzen, T., \& Manterola, C. (2017). Técnica de muestreo sobre una población a estudio. International Journal of Morphology, $35 \quad$ (1), 227-232. http://dx.doi.org/10.4067/S0717-95022017000100037

Paredes, D. C., \& Moreno, M. C. M. (2016). Influencia de la comunicación directa de las agencias de viaje en el turismo emisivo merideño. SABER, Revista Multidiciplinaria del Consejo de Investigación de la Universidad de Oriente, 28(1), 125-136. Recuperado de http://ve.scielo.org/scielo.php?script=sci_arttext\&pid=S131501622016000100013

Perona, B. E., \& Molina, E. V. (2016). Evolución y etapas del desarrollo turístico en la provincia de Córdoba, Argentina: ¿Cuán lejos está el ideal del turismo sustentable? Cuadernos de turismo, (37), 323-349. https://doi.org/10.6018/turismo.37.256261

Prada, J., \& Pesántez, S. (2017). Satisfacción y Motivación en Destinos Culturales: Tipología de los turistas atraídos por el patrimonio inmaterial en Cuenca (Ecuador). Diálogo andino, (52), 77-91. http://dx.doi.org/10.4067/S071926812017000100077

Pritchard, A., \& Morgan, N. J. (2011). Culture, identity and tourism representation: marketing Cymru or Wales? Tourism Management, 22(2), 167-179. 10.1016/S0261-5177(00)00047-9 
Ramírez, F., \& Zwerg, A. (2012). Metodología de la investigación: más que una receta. AD-minister, (20), 91-111. Recuperado de http://hdl.handle.net/11407/3306

Rendón, M., Villasís, M., \& Miranda, M. (2016). Estadística descriptiva. Revista Alergia

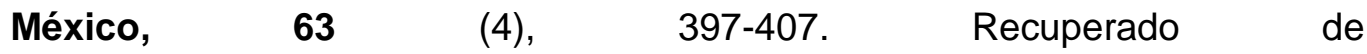
https://www.redalyc.org/pdf/4867/486755026009.pdf

Rodríguez, A. R., \& Quijano, O. G. (2017). El mercado de lugares como herramienta estratégica para el municipio de Viotá (Cundimarca, Colombia). Revista Escuela de Administración de Negocios, (83), 119-139. 10.21158/01208160.n83.2017.1822

Rodríguez, D., \& Granados, P. (2017). Diagnóstico de competitividad del turismo en Boyacá (Colombia). Revista Facultad de Ciencias Económicas: Investigación y Reflexión, 15(2), 193-205. https://doi.org/10.18359/rfce.3073

Sáez, L., Mediano, L., \& Elizagarate, V. (2011). Creación y desarrollo de marca ciudad. Análisis de los registros de marca de las principales ciudades españolas. Revista de Dirección y Administración de Empresas, 18, 125-156. Recuperado de http://hdl.handle.net/10810/9562

Sánchez, F., \& Moura, R. (2005). Ciudades-modelo: estrategias convergentes para su difusión internacional. EURE (Santiago), 31(93), 21-34. Recuperado de https://www.redalyc.org/articulo.oa?id=19609302

Segovia, C., \& Gómez, F. (2017). Una aproximación al estudio de la marca ciudad. Aplicación a la ciudad de Almería. XXIX Congreso de Marketing AEMARK 2017, pp 1300-1305. ESIC. Recuperado de https://hdl.handle.net/11441/78129

Stern, E., \& Krakover, S. (1993). The Formation of a Composite Urban Image. Geographical Analysis, 25(2), 130-146. 10.1111/j.1538-4632.1993.tb00285.x

Vargas, M. V. R., Ocaña, Á. F. O., \& Chaviano, E. L. M. (2017). Modelo para la gestión integrada del turismo comunitario en Ecuador, caso de estudio Pastaza. REVESCO. Revista Cooperativos, (123), 250-275. Recuperado de https://www.redalyc.org/articulo.oa?id=36750475010 
Varisco, C. (2005). Recursos comerciales en centros urbanos. Aportes y transferencias, 9(2), 112-126. Recuperado de http://nulan.mdp.edu.ar/306/

Yejas, D. A. (2016). Estrategias de marketing digital en la promoción de Marca Ciudad. Revista escuela de administración y negocios, 80, 59-72. https://doi.org/10.21158/01208160.n80.2016.1457 